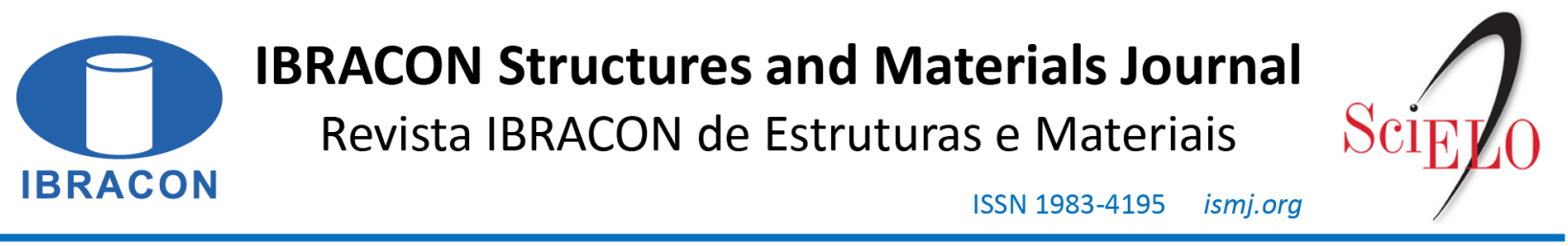

ORIGINAL ARTICLE

\title{
The cover thickness design of concrete structures subjected to chloride ingress from RBDO solution technique
}

\section{Determinação da espessura do cobrimento de estruturas em concreto sujeitas ao ingresso de cloretoes pela técnica RBDO}

\author{
Giovanni Pais Pellizzer ${ }^{\mathrm{a}}$ (D) \\ Edson Denner Leonel ${ }^{\mathrm{b}}$
}

${ }^{a}$ Universidade Federal de Mato Grosso do Sul - UFMS, Faculdade de Engenharia, Arquitetura e Geografia, Campo Grande, MS, Brasil

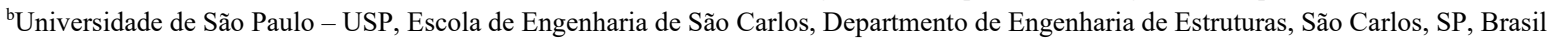

Received 22 October 2019

Accepted 05 June 2020

\begin{abstract}
Diffusion is the principal transport mechanism of chloride ions into concrete pores. The chlorides trigger the reinforcements' depassivation when its concentration at the concrete/reinforcement interface reaches the threshold level. Thus, the depassivation defines the initiation stage end and the propagation stage start. The structural safety reduces widely during the propagation stage because of the various deleterious mechanisms triggered by reinforcement's corrosion. Therefore, the engineers should accurately predict and prevent the propagation stage start. The literature describes several models for evaluating the end of the initiation stage. However, few of them applies the Boundary Element Method (BEM) for this purpose, despite its known accuracy. Besides, enormous randomness affect the phenomenon. Thus, it is adequately handled solely in the probabilistic context. Optimisation techniques may be coupled in the problem modelling to propose adequate cover thickness values accounting for probabilities of failure. This study presents a Reliability-Based Design Optimisation (RBDO) approach for designing accurately the cover thickness of concrete structures subjected to chloride ingress. The BEM handles the diffusion modelling whereas the Monte Carlo simulation assesses the probabilities of failure. The RBDO is formulated in the context of Weighted Average Simulation Method (WASM), which requires only one assessment of the reliability analysis. It leads to a reliable and computationally efficient solution technique. The problem formulation and the implemented solution scheme are described herein. Moreover, one application is presented, in which the design results are interpreted properly.
\end{abstract}

Keywords: chloride diffusion, boundary element method, probabilistic modelling, RBDO, optimisation.

\begin{abstract}
Resumo: Difusão é o principal mecanismo de transporte de íons cloreto nos poros do concreto. Os cloretos conduzem a despassivação quando sua concentração na interface concreto/armadura atinge o nível limite. Nesse momento, o período de iniciação termina e o período de propagação começa. A segurança estrutural é largamente reduzida durante o período de propagação por conta dos diversos mecanismos deletérios desencadeados pela corrosão de armaduras. Então, este fenômeno deve ser prevenido. Diversos modelos têm sido propostos na literatura para a determinação do final do período de iniciação. Contudo, poucos deles utilizam o Método dos Elementos de Contorno (MEC) para este propósito, apesar da sua conhecida precisão no domínio. Além disso, o fenômeno é sujeito a enormes aleatoriedades. Assim, este é somente adequadamente modelado no contexto probabilístico. Técnicas de otimização podem ser acopladas à modelagem do problema, com o objetivo de propor valores adequados para a espessura do cobrimento levando-se em consideração probabilidades de falha. Este estudo apresenta uma abordagem Reliability Based Design Optimisation (RBDO) para o projeto adequado da espessura do cobrimento de estruturas em concreto sujeitas ao ingresso de cloretos levando-se em consideração índices de confiabilidade alvo. O MEC efetua a modelagem da difusão enquanto a simulação de Monte Carlo avalia as probabilidades de falha. O RBDO é formulado no contexto do Weighted Average Simulation Method (WASM), no qual análises de confiabilidade através do MEC são necessárias apenas uma única vez. Isso conduz a um modelo adequado e eficiente do ponto de vista de técnica computacional. A formulação do problema e a implementação da técnica de solução são descritos. Além disso, um exemplo é apresentado, no qual os resultados do projeto são adequadamente interpretados.
\end{abstract}

Palavras-chave: difusão de cloretos, método dos elementos de contorno, modelagem probabilística, RBDO, otimização.

How to cite: G. P. Pellizzer and E. D. Leonel, "The cover thickness design of concrete structures subjected to chloride ingress from RBDO solution technique," Rev. IBRACON Estrut. Mater., vol. 13, no. 5, e13502, 2020, https://doi.org/10.1590/S1983-41952020000500002 


\section{INTRODUCTION}

Structural durability is a concern in the context of engineering design, particularly in reinforced concrete (RC) structures. In recent decades, various RC structures suffered from durability-related problems, which reduce its lifetime. Alkali-aggregate reaction, cracking caused by reinforcements corrosion and sulphate expansion [1], [2], for instance, reduce the lifetime of RC structures. Nevertheless, the chloride penetration and its consequences stand out in the literature as the principal causes of durability reduction of RC structures [3]-[5].

Tuutti [6] proposed the classic scheme for RC durability assessment, in which two macro periods divide the structural lifetime, i.e., initiation and propagation. The initiation part involves the time-span from construction until depassivation. Complementarily, the propagation part starts at the reinforcements' depassivation and finishes at the structural collapse. Diffusion-like mechanisms majorly govern the initiation part whereas enormous mechanical degradations processes are triggered during the propagation part. It is well-known in the literature that the propagation is considerably shorter than the initiation [7]. Therefore, the accurate description and representation of the initiation part have principal importance for RC design because it avoids and prevents unexpected and sudden collapses associated to the degradation phenomena from propagation part.

The chloride penetration process into concrete is nonlinear and time-dependent. Besides, it is associated to various transport mechanisms such as capillarity, advection, permeation and ionic diffusion, for instance [8]. Despite the abovementioned complexities, this phenomenon has been often modelled in the literature accounting exclusively for diffusion mechanism [9]-[11]. Analytical solutions for the diffusion problem handle the modelling in various studies in the literature. In this context, it is worth mentioning the Fick's solutions [12], [13], which incorporate strong simplification assumptions. The Fick's approach accounts for semi-infinite domains and constant boundary conditions along time. These assumptions restrict the accurate representation of chloride ingress in real-world problems, which make it nonrobust and inaccurate for a large number of applications.

Numerical methods provide alternative solution schemes for chloride diffusion modelling. Among them, it is worth citing the Boundary Element Method (BEM). The BEM represents accurately the diffusion problem by writing the governing differential equations into an integral form along the body's boundary. Therefore, the BEM reduces the order of mesh dimensionality by one, i.e., plane problems contain unidimensional BEM elements. Besides, BEM does not require a domain mesh. Because domain meshes (domain approximations) are avoided, the BEM enables the accurate evaluation of internal fields. This aspect has high importance for chloride diffusion modelling, in which chloride concentration at the reinforcements interface must be accurately evaluated along time. Moreover, the mesh is positioned only at the boundary. Thus, the problem can be solved through a small system of algebraic equations leading to computational efficiency [14], [15]. In addition, the BEM enables the representation of time dependent boundary conditions and complex geometries. These aspects make it superior to the classical analytical solutions.

It is worth remarking that randomness affect widely the chloride ingress modelling into concrete pores. Experimental studies demonstrate such observation [16], [17], which make the deterministic approach inefficient. The random behaviour governs, for instance, the chloride concentration values at the structural surface [18], [19] and the threshold chloride concentration for the reinforcements' depassivation [20]. Besides, the concrete mixture components are essentially random in space [21], [22], which introduces important randomness on the coefficient of diffusion. Therefore, the chloride ingress modelling into concrete pores by diffusion-like approaches requires probabilistic schemes for the accurate phenomena representation.

Such coupling procedure, i.e., the coupling of robust and accurate diffusion models to reliability algorithms, provides important constraints for the proposition of optimisation formulations. In this case, the probability of failure values along time can be utilised as constraints for determining optimised design for cover thickness, maintenance intervals and concrete mixtures, for instance. It is worth mentioning that optimisation formulations have been required widely in structural engineering once it enables economy and rational design.

In this context, Mori and Ellingwood [23], [24] demonstrated the relevance of inspection, repair and maintenance into the reliability of RC structures. The Bayesian scheme has been applied for updating the damage function along time after inspection and repair procedures. Therefore, the trade-off analysis between inspection/repair costs and reliability is addressed adequately.

The probabilistic evolution of mechanical damage in RC bridge decks subjected to reinforcements' corrosion triggered by chloride ingress is presented by Enright and Frangopol [25], [26]. In their study, the Monte Carlos simulation (MCS) assesses the probability of failure. Besides, the Bayesian updating technique enables the optimisation modelling of inspection intervals, which provides optimised conditions for bridge operation. Similar developments have been proposed by Biondini et al. [27], in which the researches applied the cellular automata scheme during the diffusion modelling. 
The pioneer study of Val and Stewart [28] addresses the life-cycle cost analysis of RC structures in marine environments. The durability requirements and different repair strategies have been accounted into the limit states of the optimisation modelling. The influence of climate-changes in the durability of RC structures has been studied by El Hassan et al. [29]. The proposed model handles the randomness over moisture and temperature caused by climatechanges. Moreover, uncertainty quantification associated to the diffusion of chlorides into the concrete pores has been performed. Climate-change effects have been also studied by Stewart et al. [30]. The authors analysed the growth on the probability of depassivation caused by the climate-changes. Moreover, their study reports that 1 of $6 \mathrm{RC}$ structures will present loss of performance caused by environmental conditions. Finally, they conclude that small increase on the cover, such as 5 or $10 \mathrm{~mm}$, will improve substantially the structural performance against the climate-change. Optimisation strategies have been utilized by Bastidas-Arteaga and Stewart [31]. These authors propose mitigatory actions against the impacts of climate-change in RC structures.

Finally, Andrade [32] suggests the proposition of an additional limit state in RC structures design codes. Such limit state refers to the corrosion initiation. The author puts in check the reliability indexes of FIB Model Code 2010 and claims for improvements on the design procedures.

The present study contributes in this complex and ebullient scientific domain by proposing an optimisation model. The model determines the cover thickness of RC structures accounting for a target reliability value and the randomness associated to the chloride diffusion phenomenon. The transient BEM approach solves the chloride diffusion modelling along time. The potential (chloride concentration) is accurately evaluated because BEM does not require a domain mesh. The Monte Carlo simulation (MCS) assesses the probabilities of failure. The coupling of transient BEM and MCS is reliable due to the computational efficiency of BEM in the problem. Finally, the optimisation problem is formulated in the context of Reliability Based Design Optimisation (RBDO) approach. The Weighted Average Simulation Method (WASM) scheme solves the optimisation problem, which requires only one reliability analysis per optimisation iteration. The problem formulation and its implementation solution scheme are detailed described herein. Finally, the performance of the proposed model is illustrated through one application. The design results are interpreted and it could be utilised for further calibration of RC design codes.

\section{The transient BEM approach}

The differential equation for transient potential problems represents the transient chloride ingress process into concrete pores along time. This equation is as follows:

$$
\nabla^{2} u-\frac{1}{\kappa} \frac{\partial u}{\partial t}=0
$$

in which $u$ represents the potential or chloride concentration, $\kappa$ indicates the domain-related parameter such as thermal diffusivity or coefficient of diffusion, for instance, and $t$ is the time.

The solution of the last differential equation requires the enforcement of boundary conditions, which are as follows:

\section{- Dirichlet: $u=\bar{u}$ at $\Gamma_{1}$}

- Neumann: $q=\bar{q}=\frac{d u}{d \eta}$ at $\Gamma_{2}$

where $\bar{u}$ is the prescribed potential values, $\bar{q}$ refers to the prescribed flux values, $\tilde{\mathrm{A}}_{1}$ and $\tilde{\mathrm{A}}_{2}$ represent the boundaries in which potential or flux are prescribed, respectively. It is worth mentioning that the body's boundaries are: $\Gamma=\Gamma_{1} \cup \Gamma_{2}$. In addition, the flux is associated to the potential as follows: $=\frac{d u}{d \eta}$. Thus, the flux represents the directional derivative of $u$ in relation to the outward normal vector $\eta$. The present study handles the chloride diffusion modelling into concrete pores. In this complex transient problem, potential values indicate the chloride concentration along time and the flux refers to the chloride flux along the time.

Equation 1 leads to a boundary integral representation by applying either the finite differences technique, the Laplace transform or the time dependent fundamental solutions [14], [33]-[35]. In this study, the latter approach has been applied. Then, the time dependent fundamental solutions, the weighted residuum technique and the classical limit analysis carried out by BEM lead to the following boundary integral equation: 
$c(\underline{\xi}) u\left(\underline{\xi}, t_{F}\right)=\kappa \int_{t_{0}}^{t_{F}} \int_{\Gamma} q(\underline{x}, t) u^{*}\left(\underline{\xi}, \underline{x}, t_{F}, t\right) d \Gamma(\underline{x}) d t-\kappa \int_{t_{0}}^{t_{F}} \int u(\underline{x}, t) q^{*}\left(\underline{\xi}, \underline{x}, t_{F}, t\right) d \Gamma(\underline{x}) d t$

in which $u^{*}$ and $q^{*}$ represent the time-dependent fundamental solutions for potential and flux, respectively, $\underline{\xi}$ represents the source points, $t_{0}$ is the initial time, $\underline{x}$ indicates the field points, $t_{F}$ represents the observation time and $c$ is the classical BEM free term. The free-term is unity for source points positioned at the domain. Besides, $c$ equals 0.5 for source points at smooth boundary geometries. The time-dependent fundamental solutions are as follows [14], for the plane case:

$u^{*}\left(\underline{\xi}, \underline{x}, t_{F}, t\right)=\frac{1}{4 \pi \kappa \tau} \exp \left(-\frac{r^{2}}{4 \kappa \tau}\right)$

$q^{*}\left(\underline{\xi}, \underline{x}, t_{F}, t\right)=\frac{r \frac{\partial r}{\partial \eta}}{8 \pi \kappa^{2} \tau^{2}} \exp \left(-\frac{r^{2}}{4 \kappa \tau}\right)$

where $\tau=t_{F}-t, r$ is the distance between the source $\underline{\xi}$ and the field $\underline{x}$ points whereas $\frac{\partial r}{\partial \eta}=r_{, k} \eta_{k}$.

The solution of Equation 2 requires temporal and spatial integrations [14]. The BEM solves the spatial integrations by discretising the entire boundary geometry by boundary elements, over which polynomial functions approximate the diffusion fields and geometry. High-order BEM elements can be utilised for this purpose. The temporal integrations have been solved by the constant integration scheme, which enables the analytical integration of kernels Equation 3 and Equation 4 [44]. Besides, the analytical integration along time and the Lagragian approximations on Equation 2 lead to the classical BEM algebraic system of equations $H U=G Q$, in which $H$ and $G$ are the influence matrices associated to the spatial integration of $q^{*}$ and $u^{*}$, respectively. $U$ and $Q$ contain the potential and flux at the collocations [44].

In addition to the algebraic representation previously-mentioned, the solution of the transient problem requires a time-marching process. Because the constant time integration scheme solve this time-dependent problem, the timemarching process is as follows [44]:

$\sum_{k=1}^{N T} H^{k} U^{N T-k+1}=\sum_{k=1}^{N T} G^{k} Q^{N T-k+1}$

The Gauss-Legendre integral scheme handles the spatial integrations in the problem. Besides, the singular kernels have been regularized by the Subtraction Singularity Method (SSM). For sake of clarity [44], describes in detail the implementation of this approach and presents the SSM expressions for the kernels regularization.

\section{Probabilistic modelling by Monte Carlo simulation}

The Monte Carlo simulation (MCS) technique is a well-established numerical simulation approach for uncertainty quantification purposes. In a very brief overview, the MCS assesses the probability of failure from a sampling of random variables, which describes the physical-mechanical random space. This sampling accounts for the statistical distribution assigned for each random variable (the CDF curves, for instance). Thus, the probability of failure, $P_{f}$, is assessed by MCS through the simulation of the limit state function for each random variable ensemble. Consequently, the structural failure occurs for sampling points at the failure domain. Otherwise, the safe condition occurs. The ratio between the sampling points at the failure domain and the total number of simulations leads to the probability of failure [36]. Then: 
$p_{f}=\int_{\Omega} I[\boldsymbol{x}] f_{\boldsymbol{X}}(\boldsymbol{x}) d \boldsymbol{x}=\frac{1}{n_{t}} \sum_{j=1}^{n_{t}} I\left[\boldsymbol{x}_{j}\right]=\frac{n_{f}}{n_{t}}$

in which $n_{t}$ indicates the sampling range and $n_{f}$ refers to the number of failures. The indicator function $I[x]$ is unity for failure condition and nil for safe condition. $f_{X}(x)$ represents the joint density function of the random variables $x_{i}$.

It is worth mentioning that MCS requires wide range of sampling for the accurate description of failure and safe domains. Therefore, computational time consuming models make prohibitive such type of analysis. Nevertheless, the MCS is applied herein because the BEM model has demonstrated computational efficiency. Besides, one applies the MCS because the limit state function and consequently the safe and failure spaces remain implicit during the time evolution. Therefore, gradient-based schemes such as First Order Reliability Method (FORM) or Second Order Reliability Method (SORM) could be not robust in this problem. Such approaches require derivatives of the limit state functions for assessing the probability of failure. Because the limit state functions are implicit, such derivatives must be evaluated numerically. As a result, errors during this phase may lead to inaccurate values of probability of failure. Besides, these approaches may stuck in local minima solutions, which also lead to the inaccurate values of probability of failure.

The limit state function $Y$ defines the interface between safe and failure domains. The limit state function described in Equation 7 governs the probabilistic modelling herein:

$$
Y\left(x_{i}\right)=\Xi\left(x_{i}\right)-\Psi\left(x_{i}, t\right)
$$

where $\Xi$ represents the resistance part, which in this problem is the chloride threshold content. This parameter is usually a function of concrete mixture and water/cement ratio. $\varnothing$ indicates the solicitation part and accounts for the chloride concentration at the observation point for the structural life-time. The transient BEM model provides this variable values, which in this problem are the potential values at the observation points.

\section{Optimisation problem formulation. Problem statement}

The structural modelling and design require the application of mathematical functions, which describe the evolution of the system behaviour along time. In this regard, optimisation techniques may be valuable tools because they enable the determination of proper design parameters for leading to the extreme (maximum and minima) values of such functions. The optimisation approaches have been largely desired in probabilistic modelling. Then, the optimum design parameters may be utilised accounting for the inherent uncertainties over it.

Among the coupled optimisation/probabilistic schemes available in the literature it is worth citing the reliability based design optimisation (RBDO). The RBDO approach defines functions of probabilistic parameters as constraints into the optimisation problem. The usual RBDO problem is formulated as follows [37]:

Find: $\boldsymbol{d}^{*}$

Which minimizes: $f(\boldsymbol{d})$

Subject to: $\left\{\begin{array}{c}P_{f_{i}}(\boldsymbol{d}) \leq P_{f_{T_{i}}}, i=1, \ldots, n_{L S} \\ d \in S \subset \mathbb{R}^{n_{d}}\end{array}\right.$

in which $\boldsymbol{d}^{*}$ represents the objective variables vector, $f(\boldsymbol{d})$ indicates the objective function, $P_{f_{i}}(\boldsymbol{d})$ is the probability of failure function for failure mode $i, P_{f_{T_{i}}}$ represents the target (threshold) probability of failure for the failure mode $i, n_{L S}$ indicates the number of limit states, $s$ is the allowable design domain and $n_{d}$ is the number of design variables.

Such problem may be alternatively formulated as follows:

Find: $\boldsymbol{d}^{*}$

Which minimizes: $f(\boldsymbol{d})$ 
Subject to: $\left\{\begin{array}{c}\beta_{i}(\boldsymbol{d}) \geq \beta_{T_{i}}, i=1, \ldots, n_{L S} \\ d \in S \subset \mathbb{R}^{n_{d}}\end{array}\right.$

where $\beta_{i}(\boldsymbol{d})$ indicates the reliability index for the failure mode $i$ and $\beta_{T_{i}}$ represents the target (threshold) reliability index for the failure mode $i$.

It is worth citing that Equation 8 and Equation 9 may contain equalities and inequalities constraints. Besides, such equations also handle system reliability problems, in which the system probabilities of failure and system reliability index are accounted. Finally, the probabilistic constraints for the individual failure modes can coexist with the probabilistic system failure constraints. Analytical solutions for RBDO problems are available for a narrow number of problems, in which objective and constraints functions are simpler. Thus, complex and real-world problems require simulation-based approaches. These methods handle adequately nonlinear response problems and non-Gaussian random variables. Alternatively, approximation methods may be adopted, which demonstrate adequate performance in linear response problems and Gaussian random variables.

The performance of RBDO solution schemes has been analysed by Rashki et al. [38]. In their study, the authors proposed an interesting strategy for incorporating the reliability analysis into the optimisation step. Such strategy utilises the concepts of sampling weight and weighting flexibility for assessing the probability of failure. This approach consists of generating samples uniformly distributed into the design space, which enable the optimised configurations. Therefore, only one probabilistic simulation procedure is required for each individual sample. This characteristic has major importance within complex systems behaviour, where usually complex and computational costly models have been required.

The weighted average simulation method (WASM), presented by Rashki et al. [39], is composed of simple procedures, in which MCS has been applied. The first step consists of generating $n_{\text {sim }}$ samples uniformly distributed into the design space for each random variable. Such sample accounts for predetermined bounds, which accelerate the responses. Then, the weight $w_{i}$ for each sample $i$ is assessed through the probability density functions $f_{j}($.$) . for each$ random variable as follows:

$w_{i}=\prod_{j=1}^{n_{R V}} f_{j}(i)$

The probability of failure $P_{f}$ is assessed through the indicator function $I$ in each sample $i$, as usual in MCS. Such indicator is weighed by $w_{i}$ as follows:

$P_{f}=\frac{\sum_{i=1}^{n_{\text {sin }}} I_{i} w_{i}}{\sum_{i=1}^{n_{\text {sim }} w_{i}}}$

The main advantage of this solution technique involves the assessment of updated probability of failure values, $P_{f}^{\prime}$ , without the requirement of additional evaluations of the indicator function. If statistical parameters and/or the type of a random variable ${ }_{j}$ are modified, the weights are recalculated as follows:

$w_{i}^{\prime}=\prod_{j=1}^{n_{R V}} f_{j}^{\prime}(i)$

Therefore, the updated values for the probability of failure are straightforward assessed as follows:

$P_{f}^{\prime}=\frac{\sum_{i=1}^{n_{\text {sin }} I_{i} w_{i}^{\prime}}}{\sum_{i=1}^{n_{\text {sin }}} w_{i}^{\prime}}$ 
It is worth stressing that the indicator function is kept constant during the assessment of updated probability of failure values, $P_{f}^{\prime}$, because the sample values must not be updated. Therefore, for each iteration, only the weights must be updated. Consequently, the updated values for the probability of failure are assessed through the updated weights and the same indicator function. Such feature is named as "weighting flexibility" and is widely helpful in complex realworld problems, in which computational costly approaches have been usually required for system behaviour modelling. Besides, such advantage has major importance within RBDO techniques, in which constraints related to the probability of failure of different limit states must be updated at each optimisation iteration. Then, this technique makes reliable the analysis and solution of complex problems accounting for robust system behaviour models.

The methodology proposed by Rashki et al. [38], through the coupling the WASM into RBDO problems, is utilised herein. Such methodology consists of five steps as follows:

\section{Step 1: Uniform sample generation into the design space}

Regardless the random variables type, samples uniformly distributed along the design space are generated for each random variable handled in the problem. The upper and lower bounds for each of them have been determined from the estimated reliability index for the problem. Rashki et al. [39] provide details for choosing properly this sampling interval. Thus, a sample vector $\boldsymbol{x}_{j}$ of the random variable $j$ have sample values $x_{j, i}$, as follows:

$\boldsymbol{x}_{j}=\left\{x_{j, 1}, x_{j, 2}, \ldots, x_{j, i}, \ldots, x_{j, n_{s i n}}\right\}$

\section{Step 2: Indicator function assessment}

The sample values generated in step 1 simulate the limit state functions. Then, the indicator function is the unit when the limit state function is negative. In this case, the sample belongs to the failure domain, $\grave{\mathrm{U}}_{f}$. Otherwise, the indicator function is nil and the safe domain, $\grave{U}_{S}$, is assessed.

\section{Step 3: Probability of failure assessment using the weighting flexibility scheme}

It is worth mentioning that the samples at the safe domain are potential solutions for the RBDO problem. For each of these candidate solutions, the probability of failure is assessed through Equation 13. In this procedure, the sample value at the design space is assumed as the mean value of their respective probability distribution. Then, sample weights are recalculated from Equation 12, which lead to the updated values of the probability of failure. Therefore, the probabilities of failure associated to the candidate samples can be assessed from only one indicator function evaluation process.

\section{Step 4: The candidate samples choice procedure}

The probability of failure, $P_{f}$, for each sample at the safe domain has been assessed. Then, the samples are eliminated if $P_{f}$ is higher than $P_{f_{T}}$. The $P_{f_{T}}$ represents the threshold probability of failure and indicates a constraint in the optimisation problem. The remaining samples belong to the reliable domain. Consequently, the optimal solution may be achieved among them.

\section{Step 5: Objective function evaluation accounting for the samples in the reliable domain}

The last step concerns the objective function evaluation. Then, such function is evaluated for each of the samples at the reliable domain, as described in step 4. The optimal solution leads to the lowest value of the objective function.

The BEM model interacts with the optimisation methodology in the indicator function procedure (step 2). Thus, the indicator function is evaluated only once for each sample throughout the entire optimisation process. This is the main advantage of this methodology, as previously mentioned. The summary of the optimisation process steps is illustrated in Figure 1. 


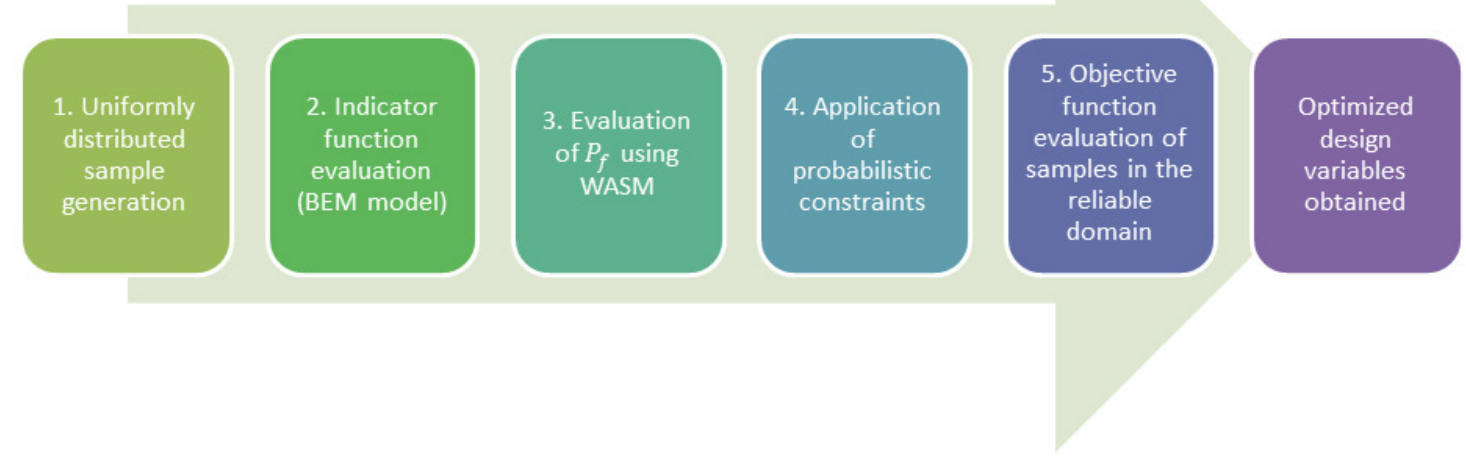

Figure 1. Flowchart of the proposed numerical approach.

\section{Solution problem}

The framework previously presented has been utilised for optimising the cover thickness of concrete structures subjected to chloride ingress. Because this problem is subjected to huge randomness, its solution is properly handled solely in the context of probabilistic modelling. The chloride diffusion phenomenon into concrete pores is handled through the robust transient potential BEM approach. Moreover, the WASM scheme handles the optimisation problem accounting for randomness, which leads to the optimum cover thickness value.

For sake of simplicity, the cross-section illustrated in Figure 2 has been accounted in the following analyses. This cross-section contains a reinforcement of $10 \mathrm{~mm}$ diameter, in which an initial cover of $40 \mathrm{~mm}$ has been assumed. It is worth mentioning that this reinforcement has been utilized solely to illustrate the cover limit. The reinforcement itself has not been accounted in the modelling.

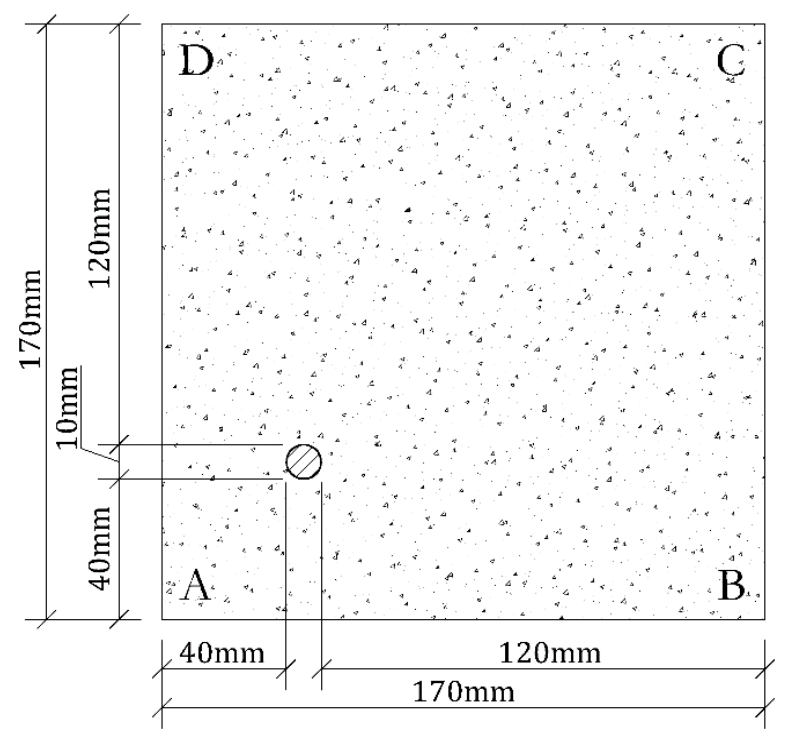

Figure 2. Cross-section geometry.

This analysis handles the two different boundary conditions illustrated in Figure 3. The case 1 involves the onedirectional flow condition whereas case 2 represents the fully two-dimensional flow condition. 

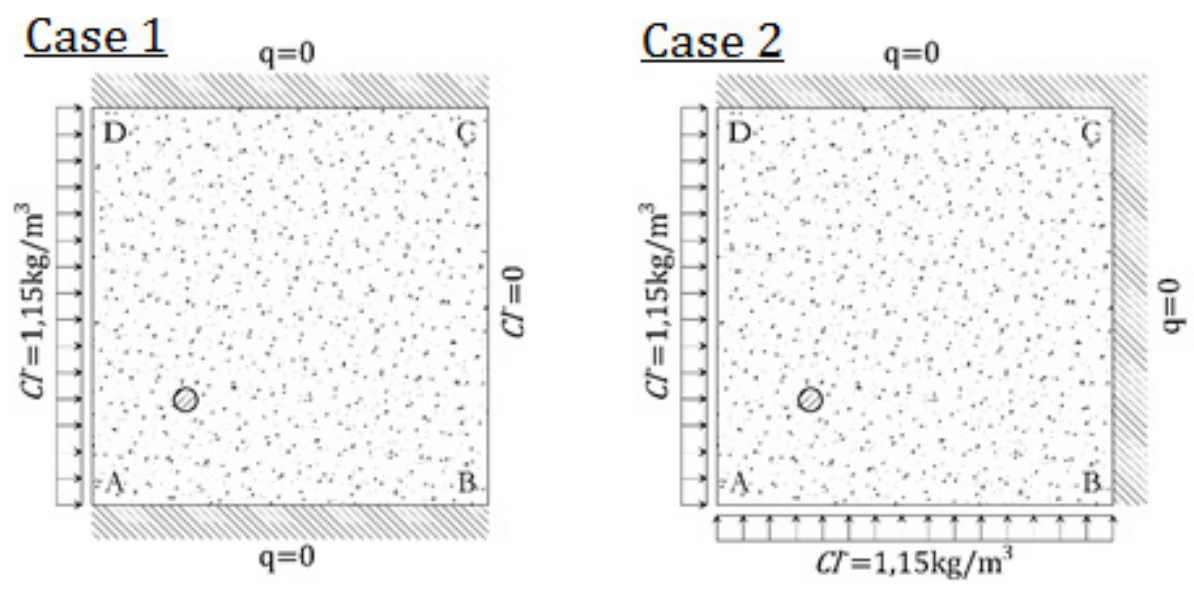

Figure 3. Boundary conditions. Case 1 and Case 2.

The limit state function for the probabilistic modelling has been defined as a function of the depassivation time as follows:

$G=t_{\text {dep. }}-t_{\text {s.d.l }}$

where $t_{d e p}$. indicates the time predicted as a function of random variables for depassivation phenomenon start. Such variable has been evaluated by the transient BEM approach. $t_{\text {s.d.l. }}$ represents the structural lifetime, which is usually defined during the design phase.

The random variables parameters are illustrated in Table 1.

Table 1. Random variables parameters.

\begin{tabular}{ccccc}
\hline Parameter & Distribution type & Mean & C.V. & Reference \\
\hline$C_{\text {lim }}$ & Uniform & $0.90 \mathrm{~kg} / \mathrm{m}^{3}$ & 0.15 & Mehta and Monteiro [42] \\
$\kappa_{0}$ & Lognormal & $23.0572 \mathrm{~mm}^{2} / \mathrm{year}(\mathrm{w} / \mathrm{c}=0.4)$ & 0.30 & Bentz et al. [17] \\
\hline$C_{0}$ & Lognormal & $1.15 \mathrm{~kg} / \mathrm{m}^{3}$ & 0.30 & McGee [43]/ Val and Stewart [28] \\
\hline COv & Normal & $40.00 \mathrm{~mm}$ & 0.30 & - \\
\hline
\end{tabular}

where $C_{\lim }$ indicates the chloride threshold content for depassivation, $\kappa_{0}$ represents the chloride diffusion coefficient, $C_{0}$ is the chloride concentration at the structural surface and $c o v$ is the concrete cover thickness. The latter parameter refers to the objective parameter, i.e., the parameter to be optimised.

Besides, the chloride concentration (potential value) has been calculated at the random $\operatorname{cov}_{i}$ position, which corresponds to the sample value $i$ of cover thickness. The transient BEM model determines such values along time. For case 1 , the chloride concentration has been evaluated along a parallel line to the boundary AB. For case 2 , the chloride concentration has been determined along the diagonal AC. Figure 4 illustrates such positions. It is worth mentioning that the parameter $\operatorname{cov}_{\mu}$ represents the mean concrete cover thickness, which has been assumed as $40 \mathrm{~mm}$.

The diffusion modelling is handled by the BEM. The BEM mesh is composed of 68 discontinuous isoparametric linear elements with $10 \mathrm{~mm}$ length each. It lead to 136 source points and 272 degrees of freedom. The fundamental kernels are integrated with only 10 Gauss points per element. Moreover, the time discretisation is performed through 25 time steps, from year 0 to year 50. It is worth mentioning that space and time discretisations have been determined accounting for standard convergence procedure. Then, further refined discretisations do not introduce significant changes into the diffusion fields modelling. The probabilistic MCS simulations have been handled through 10,000 samples for each random variable. 

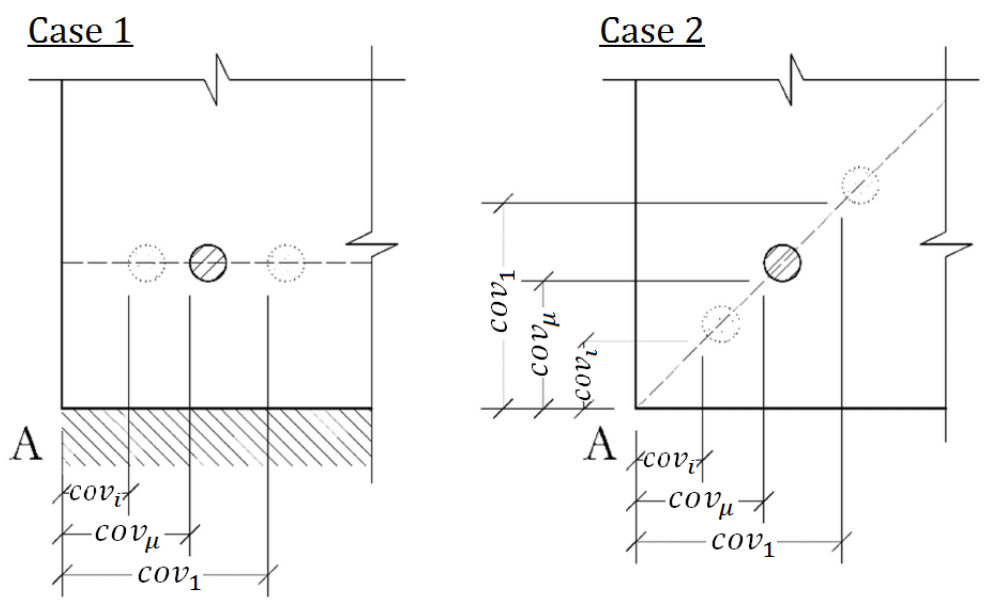

Figure 4. Cover values for chloride concentration assessment. Case 1 and Case 2.

The framework previously presented has been applied accounting for deterministic structural lifetimes of 30, 40 and 50 years. Moreover, the target reliability indexes $\beta_{T}$ are assumed into the interval -1.0 to 3.0. From such data, the WASM approach provides the optimised concrete cover thickness. The evolution of concrete cover thickness for boundary conditions defined from case 1 and case 2 is illustrated in Figure 5.

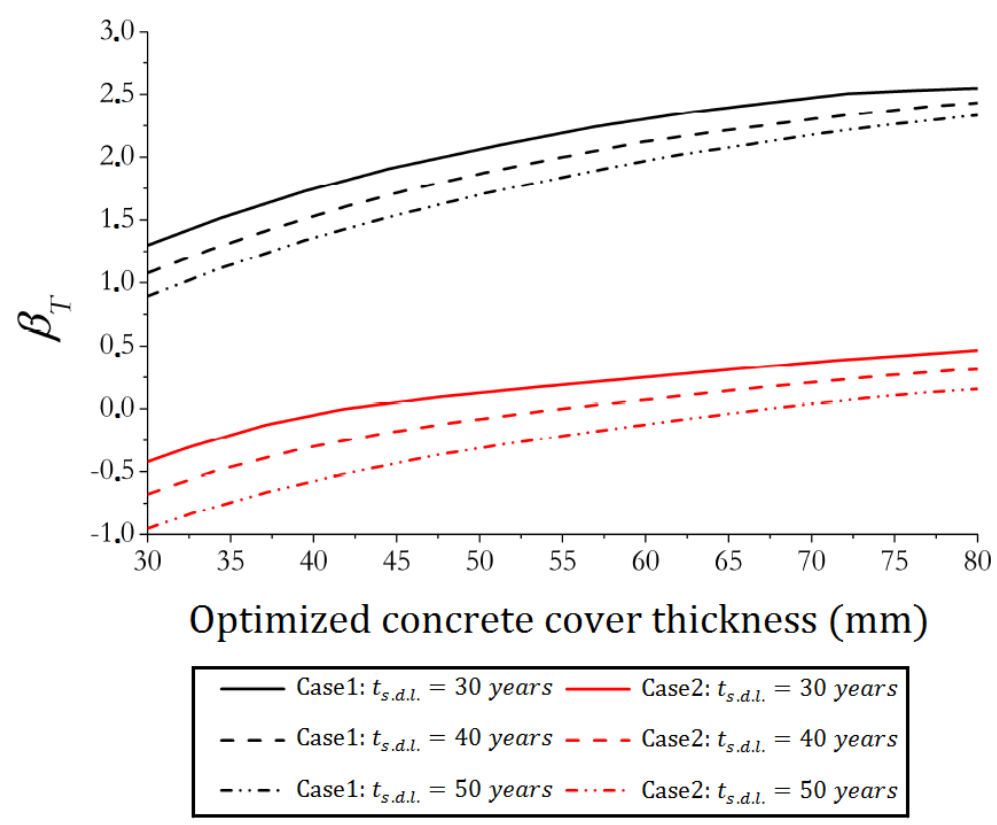

Figure 5. Optimised concrete cover thickness. $\beta_{T}$ condition. Case 1 and Case 2.

Figure 6 presents an equivalent illustration, in which the evolution of cover thickness is presented as a function of the target probability of failure.

It is worth emphasizing the large difference behaviour for cases 1 and 2 when the same cover thickness value is accounted. Similar observation can be performed in Figure 5, in terms of target probability of failure values. Besides, one observes the cover thickness values in the range from $30 \mathrm{~mm}$ to $80 \mathrm{~mm}$. For case 1, the associated target reliability index range is 0.8 to 2.6. For case 2, the correspondent range is -1.0 to 0.5 . Such behaviour corroborates with responses presented in literature [40], in which two-dimensional flux conditions lead to severe conditions for depassivation in 
comparison with one-dimensional case. These results put in check models based exclusively in one-dimensional conditions, such as those based on Fick's law.

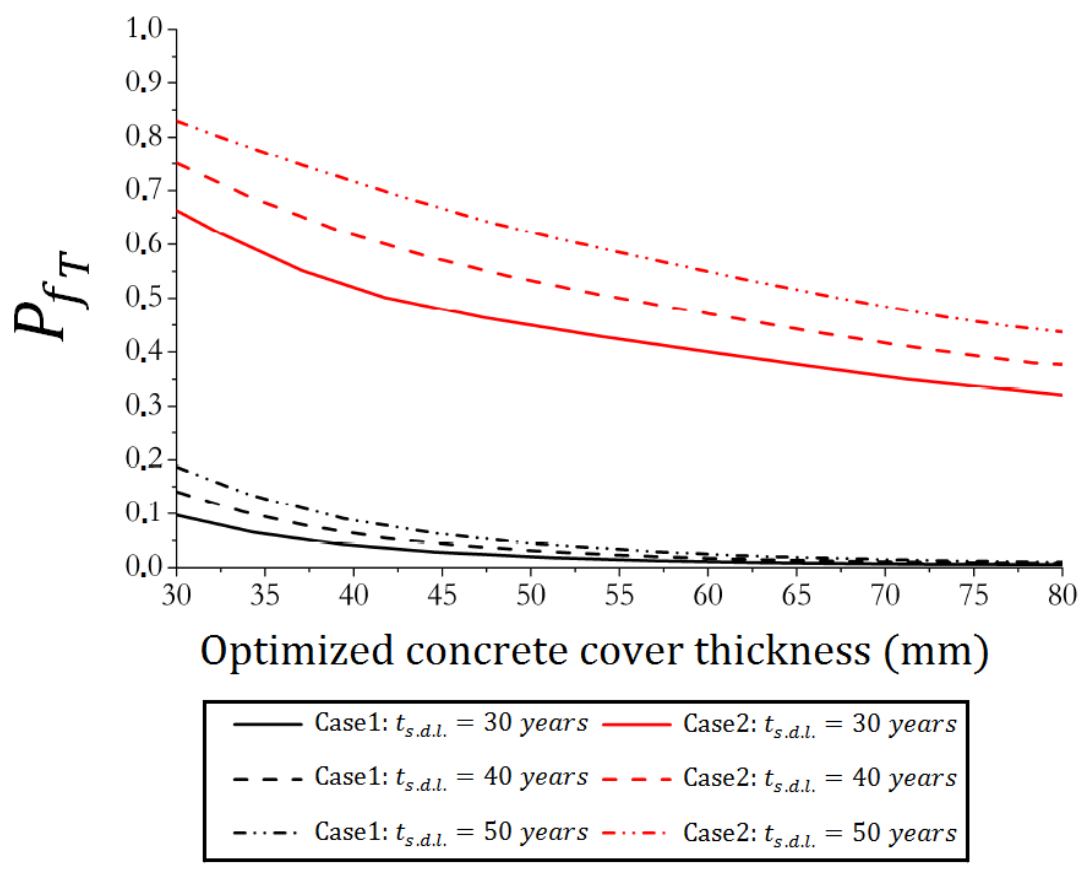

Figure 6. Optimised concrete cover thickness. $P_{f T}$ condition. Case 1 and Case 2.

Besides, the triplets of curves illustrated in Figure 6 demonstrate convergence behaviour, i.e., such curves tend to the horizontal position for increasing values of cover thickness, as expected. Because of such behaviour, the increase on the cover thickness values does not lead to similar increase on the durability safety level. Thus, from certain values of thickness, the safety level is not effectively increased, which may indicate threshold values of cover.

It is worth stressing the nonlinear behaviour between $\beta_{T}$ and $P_{f_{T}}$, in which $P_{f_{T}}=\Phi\left(-\beta_{T}\right)$. Such nonlinear dependency lead to different growth rates for curves, as observed in Figure 5 and Figure 6 . Then, linear increments into cover thickness values do not lead to the similar growth rates in $\beta_{T}$. In the context of design, it means that the increase in the cover thickness in case 2 (two-dimensional flow) leads to the higher safety improvement than the same increase in cover thickness on case 1 (one-dimensional flow). This result emphasizes the importance of controlling and designing the adequate cover thickness for the proper protection of reinforcements.

The JCSS [41] recommends target reliability indices for irreversible service limit states in the range from 1.3 to 2.3. Figure 5 demonstrates that the three curves for case 1 (one-dimensional flow) respect almost entirely the minimum value of 1.3. The same behaviour has not been observed for case 2 (two-dimensional flow). Because the increase on the cover thickness values does not seem to be effective in the latter case, it is suggestable to reduce the water/cement ratio of the concrete mixture. It reduces the velocity of the chloride diffusion process and, consequently, enables accomplishing with JCSS [41] requirements.

\section{CONCLUSIONS}

This study demonstrates the performance of the coupling between transient BEM model and a RBDO formulation through the WASM scheme. The objective is the assessment of optimum cover thickness values accounting for randomness. The diffusion phenomenon has been accurately modelled by the BEM, which handles transient potential and flux conditions. Besides, the diffusion model enables the representation of one and two dimensional flux conditions. The WASM approach is widely adequate into an RBDO design. This optimisation scheme requires the probability of failure assessment only once for each point into the reliable space. Thus, the coupled scheme is efficient in terms of computational time consuming. 
The performance and analyses results have been handled for one and two dimensional flux conditions. In addition, the differences among the results are discussed once the cover values for cases 1 and 2 are considerable different.

The proposed framework may be utilised for suggesting proper cover thickness values as a function of target reliability. Thus, in the absence of design code recommendations, this model is largely helpful. Moreover, parametric analyses may be helpful for improving the current durability recommendations of the Brazilian design code. Thus, the information of reliability is properly accounted into the cover prescription.

Such model may be improved in the future by incorporating complex diffusion effects such as chloride binding capacity and concrete cracking, for instance. In this case, the proposed framework is still valid. It requires only the update of the diffusion modelling. Such developments are due in course by the research group of the senior author of this study.

\section{REFERENCES}

[1] D. Bru, A. González, F. J. Baeza, and S. Ivorra, "Seismic behavior of 1960's RC buildings exposed to marine environment," Eng. Fail. Anal., vol. 90, pp. 324-340, 2018, http://dx.doi.org/10.1016/j.engfailanal.2018.02.011.

[2] J. R. A. Goncalves, Y. Boluk, and V. Bindiganavile, "Crack growth resistance in fibre reinforced alkali-activated fly ash concrete exposed to extreme temperatures," Mater. Struct., vol. 51, no. 2, pp. 3, 2018, http://dx.doi.org/10.1617/s11527-018-1163-6.

[3] F. Shaikh, "Effect of cracking on corrosion of steel in concrete," Int. J. Concr. Struct. Mater., vol. 12, no. 1, pp. 1-12, 2018, http://dx.doi.org/10.1186/s40069-018-0234-y.

[4] A. Silva, R. Neves, and J. Brito, "Statistical modelling of carbonation in reinforced concrete," Cement Concr. Compos., vol. 50, pp. 73-81, 2014, http://dx.doi.org/10.1016/j.cemconcomp.2013.12.001.

[5] T.-B. Tran, E. Bastidas-Arteaga, F. Schoefs, and S. Bonnet, "A Bayesian network framework for statistical characterisation of model parameters from accelerated tests: application to chloride ingress into concrete," Struct. Infrastruct. Eng., vol. 14, no. 5, pp. 580-593, 2018, http://dx.doi.org/10.1080/15732479.2017.1377737.

[6] K. Tuutti, Corrosion of Steel in Concrete Swedish. Stockholm: Cem. Concr. Res. Inst., 1982, 460 p.

[7] E. A. P. Liberati, C. G. Nogueira, E. D. Leonel, and A. Chateauneuf, "Nonlinear formulation based on FEM, Mazars damage criterion and Fick's law applied to failure assessment of reinforced concrete structures subjected to chloride ingress and reinforcements corrosion," Eng. Fail. Anal., vol. 46, pp. 247-268, 2014, http://dx.doi.org/10.1016/j.engfailanal.2014.09.006.

[8] L. Saad, A. Aissani, A. Chateauneuf, and W. Raphael, "Reliability-based optimization of direct and indirect LCC of RC bridge elements under coupled fatigue-corrosion deterioration processes," Eng. Fail. Anal., vol. 59, pp. 570-587, 2016, http://dx.doi.org/10.1016/j.engfailanal.2015.11.006.

[9] E. Bastidas-Arteaga and F. Schoefs, "Stochastic improvement of inspection and maintenance of corroding reinforced concrete structures placed in unsaturated environments," Eng. Struct., vol. 41, pp. 50-62, 2012, http://dx.doi.org/10.1016/j.engstruct.2012.03.011.

[10] A. Ben-Fraj, S. Bonnet, and A. Khelidj, "New approach for coupled chloride/moisture transport in non-saturated concrete with and without slag," Constr. Build. Mater., vol. 35, pp. 761-771, 2012, http://dx.doi.org/10.1016/j.conbuildmat.2012.04.106.

[11] P.-T. Nguyen, E. Bastidas-Arteaga, O. Amiri, and C.-P. El Soueidy, "An efficient chloride ingress model for long-term lifetime assessment of reinforced concrete structures under realistic climate and exposure conditions," Int. J. Concr. Struct. Mater., vol. 11, no. 2, pp. 199-213, 2017, http://dx.doi.org/10.1007/s40069-017-0185-8.

[12] M. G. Stewart, "Spatial variability of pitting corrosion and its influence on structural fragility and reliability of RC beams in flexure," Struct. Saf., vol. 26, no. 4, pp. 453-470, 2004, http://dx.doi.org/10.1016/j.strusafe.2004.03.002.

[13] K. A. T. Vu and M. G. Stewart, "Structural reliability of concrete bridges including improved chloride-induced corrosion models," Struct. Saf., vol. 22, no. 4, pp. 313-333, 2000, http://dx.doi.org/10.1016/S0167-4730(00)00018-7.

[14] L. C. Wrobel, The Boundary Element Method: Applications in Thermos-fluids and Acoustics, vol. 1. New York: John Wiley \& Sons; 2002.

[15] E. D. Leonel and W. S. Venturini, "Non-linear boundary element formulation applied to contact analysis using tangent operator," Eng. Anal. Bound. Elem., vol. 35, no. 12, pp. 1237-1247, 2011, http://dx.doi.org/10.1016/j.enganabound.2011.06.005.

[16] H. E.-D. H. Seleem, A. M. Rashad, and B. A. El-Sabbagh, "Durability and strength evaluation of high-performance concrete in marine structures," Constr. Build. Mater., vol. 24, no. 6, pp. 878-884, 2010, http://dx.doi.org/10.1016/j.conbuildmat.2010.01.013.

[17] D. P. Bentz, E. J. Garboczi, Y. Lu, N. Martys, A. R. Sakulich, and W. J. Weiss, "Modeling of the influence of transverse cracking on chloride penetration into concrete," Cement Concr. Compos., vol. 38, pp. 65-74, 2013, http://dx.doi.org/10.1016/j.cemconcomp.2013.03.003.

[18] K. Y. Ann, J. H. Ahn, and J. S. Ryou, "The importance of chloride content at the concrete surface in assessing the time to corrosion of steel in concrete structures," Constr. Build. Mater., vol. 23, no. 1, pp. 239-245, 2009, http://dx.doi.org/10.1016/j.conbuildmat.2007.12.014. 
[19] S. Zhou, "Analytical model for square root increase of surface chloride concentration and decrease of chloride diffusivity," J. Mater. Civ. Eng., vol. 28, 04015181, 2016, http://dx.doi.org/10.1061/(ASCE)MT.1943-5533.0001483.

[20] M. Shakouri, D. Trejo, and P. Gardoni, "A probabilistic framework to justify allowable admixed chloride limits in concrete," Constr. Build. Mater., vol. 139, pp. 490-500, 2017, http://dx.doi.org/10.1016/j.conbuildmat.2017.02.053.

[21] M. Shekarchi, A. Bonakdar, M. Bakhshi, A. Mirdamadi, and B. Mobasher, "Transport properties in metakaolin blended concrete," Constr. Build. Mater., vol. 24, no. 11, pp. 2217-2223, 2010, http://dx.doi.org/10.1016/j.conbuildmat.2010.04.035.

[22] F. Farmani, B. Bonakdarpour, and A. A. Ramezanianpour, "pH reduction through amendment of cement mortar with silica fume enhances its biological treatment using bacterial carbonate precipitation," Mater. Struct., vol. 48, no. 10, pp. 3205-3215, 2015, http://dx.doi.org/10.1617/s11527-014-0391-7.

[23] Y. Mori and B. R. Ellingwood, "Maintaining reliability of concrete structures. I: role of inspection/repair," J. Struct. Eng., vol. 120, no. 3, pp. 824-845, 1994, http://dx.doi.org/10.1061/(ASCE)0733-9445(1994)120:3(824).

[24] Y. Mori and B. R. Ellingwood, "Maintaining reliability of concrete structures. II: optimum inspection/repair," J. Struct. Eng., vol. 120, no. 3, pp. 846-862, 1994, http://dx.doi.org/10.1061/(ASCE)0733-9445(1994)120:3(846).

[25] M. P. Enright and D. M. Frangopol, "Service-life prediction of deteriorating concrete bridges," J. Struct. Eng., vol. 124, no. 3, pp. 309-317, 1998, http://dx.doi.org/10.1061/(ASCE)0733-9445(1998)124:3(309).

[26] M. P. Enright and D. M. Frangopol, "Condition prediction of deteriorating concrete bridges using Bayesian updating," J. Struct. Eng., vol. 125, no. 10, pp. 1118-1125, 1999, http://dx.doi.org/10.1061/(ASCE)0733-9445(1999)125:10(1118).

[27] F. Biondini, F. Bontempi, D. M. Frangopol, and P. G. Malerba, "Probabilistic Service Life Assessment and Maintenance Planning of Concrete Structures," J. Struct. Eng., vol. 132, no. 5, pp. 810-825, 2006, http://dx.doi.org/10.1061/(ASCE)07339445(2006)132:5(810).

[28] D. V. Val and M. G. Stewart, "Life-cycle cost analysis of reinforced concrete structures in marine environments," Struct. Saf., vol. 25, no. 4, pp. 343-362, 2003, http://dx.doi.org/10.1016/S0167-4730(03)00014-6.

[29] J. El Hassan, P. Bressolette, A. Chateauneuf, and K. El Tawil, "Reliability based assessment of the effect of climatic conditions on the corrosion of RC structures subject to chloride ingress," Eng. Struct., vol. 32, no. 10, pp. 3279-3287, 2010, http://dx.doi.org/10.1016/j.engstruct.2010.07.001.

[30] M. G. Stewart, X. Wang, and M. N. Nguyen, "Climate change impact and risks of concrete infrastructure deterioration," Eng. Struct., vol. 33, no. 4, pp. 1326-1337, 2011, http://dx.doi.org/10.1016/j.engstruct.2011.01.010.

[31] E. Bastidas-Arteaga and M. G. Stewart, "Damage risks and economic assessment of climate adaptation strategies for design of new concrete structures subject to chloride-induced corrosion," Struct. Saf., vol. 52, pp. 40-53, 2015, http://dx.doi.org/10.1016/j.strusafe.2014.10.005.

[32] C. Andrade, "Reliability analysis of corrosion onset: initiation limit state," J. Struct. Integr. Maint., vol. 2, no. 4, pp. 200-208, 2017, http://dx.doi.org/10.1080/24705314.2017.1388693.

[33] D. Curran, M. Cross, and B. A. Lewis, "A preliminary analysis of boundary element methods applied to parabolic partial differential equations," in New Developments in Boundary Element Methods, C. A. Brebbia, Ed., Southampton: Comput. Mech. Publ., 1980.

[34] L. C. Wrobel and C. A. Brebbia, "A formulation of the boundary element method for axisymmetric transient heat conduction," Int. J. Heat Mass Transfer, vol. 24, no. 5, pp. 843-850, 1981, http://dx.doi.org/10.1016/S0017-9310(81)80007-5.

[35] L. C. Wrobel and C. A. Brebbia, "The dual reciprocity boundary element formulation for nonlinear diffusion problems," Comput. Methods Appl. Mech. Eng., vol. 65, no. 2, pp. 147-164, 1987, http://dx.doi.org/10.1016/0045-7825(87)90010-7.

[36] A. H.-S. Ang and W. H. Tang, Probability Concepts in Engineering, Emphasis on Applications to Civil and Environmental Engineering, vol. 1, 2nd ed. Hoboken: John Wiley \& Sons, 2007.

[37] R. E. Melchers and A. T. Beck, Structural Reliability Analysis and Prediction, 3rd ed. West Sussex, UK: Wiley, 2017,527 p. http://dx.doi.org/10.1002/9781119266105.

[38] M. Rashki, M. Miri, and M. A. Moghaddam, "A simulation-based method for reliability based design optimization problems with highly nonlinear constraints," Autom. Construct., vol. 47, pp. 24-36, 2014, http://dx.doi.org/10.1016/j.autcon.2014.07.004.

[39] M. Rashki, M. Miri, and M. A. Moghaddam, "A new efficient simulation method to approximate the probability of failure and most probable point," Struct. Saf., vol. 39, pp. 22-29, 2012, http://dx.doi.org/10.1016/j.strusafe.2012.06.003.

[40] D. V. Val and P. A. Trapper, "Probabilistic evaluation of initiation time of chloride-induced corrosion," Reliab. Eng. Syst. Saf., vol. 93, no. 3, pp. 364-372, 2008, http://dx.doi.org/10.1016/j.ress.2006.12.010.

[41] Joint Committee on Structural Safety. “JCSS Probabilistic model code.” Denmark, 2001, 179 p. [Online]. Available: http://www.jcss.ethz.ch/

[42] P. K. Mehta and P. J. M. Monteiro, Concrete: Microstructure, Properties, and Materials. New York: McGraw-Hill , 2005.

[43] R. McGee, "Modelling of durability performance of tasmanian bridges," in ICASP8 Applications of Statistics and Probability in Civil Engineering, vol. 1, R. E. Melchers and M. G. Stewart, Eds. Rotterdam: Balkema, 1999, pp. 297-306. 
[44] G. P. Pellizzer and E. D. Leonel, "Probabilistic corrosion time initiation modelling in reinforced concrete structures using the BEM," Ibracon Struct. Mater. J., vol. 4, 10, 2012.

Author contributions: GPP implemented the numerical formulations and tested it in several problems. Besides, GPP performed the literature review and wrote this article. EDL proposed the research and supervised the PhD student GPP. EDL wrote this article and handled its review.

Editors: Bernardo FonsecaTutikian, José Luiz Antunes de Oliveira e Sousa, Guilherme Aris Parsekian. 